\begin{tabular}{|l|l|}
\hline $\begin{array}{l}\text { Postprint Version } \\
\text { Journal website }\end{array}$ & 1.0 \\
\hline $\begin{array}{l}\text { Pubmed link } \\
\text { http://www.blackwell-synergy.com/doi/abs/10.1111/j.1600-0722.2007.00439.x }\end{array}$ \\
\hline $\begin{array}{l}\text { http://www.ncbi.nlm.nih.gov/sites/entrez?Db=pubmed\&Cmd=ShowDetailView } \\
\text { \&TermToSearch=17587292\&ordinalpos=3\&itool=EntrezSystem2.PEntrez.Pubm }\end{array}$ \\
\hline$\underline{\text { DOI.Pubmed ResultsPanel.Pubmed_RVDocSum }}$
\end{tabular}

This is a NIVEL certified Post Print, more info at http://www.nivel.eu

\title{
Professional burnout and work engagement among dentists
}

\author{
HANS Te BRAKE ${ }^{1}$ ANNE-MARTHe Bouman ${ }^{2}$, RONALd GORTER ${ }^{1}$ JOHAN HOOGSTRATEN $^{1,2}$, Michiel \\ EIJKMAN $^{1}$
}

1Department of Social Dentistry and Behavioral Sciences, Academic Center for Dentistry Amsterdam (ACTA), Universiteit van Amsterdam and Vrije Universiteit, Amsterdam, the Netherlands; 2Department of Psychological Methods, Universiteit van Amsterdam, Amsterdam, the Netherlands JHM te Brake, NIVEL - Netherlands Institute for Health Services Research, PO Box 1568, 3500 BN, Utrecht, the Netherlands

Telefax: +31-30-2729729

E-mail: H.teBrake@nivel.nl

\begin{abstract}
A recent development within burnout research is the shift to its conceptual opposite: work engagement. This study aimed to unravel the concepts of burnout and work engagement, and to determine their levels among dentists. A representative sample of 497 Dutch general dental practitioners was included (survey response rate of 59\%), consisting of 372 men and 121 women (the gender of 4 dentists remained unknown). The hypothesized three-factor structure of work engagement (vigor, dedication, and absorption), as measured by the Utrecht Work Engagement Scale (UWES), was substantiated among dentists. It was also found that work engagement was related negatively to burnout, as measured by the Maslach Burnout Inventory (MBI). However, a model consisting of a reduced ('core') burnout factor and an 'enhanced' engagement factor (composed of the three original factors plus the burnout factor, personal accomplishment) showed the best fit. Overall burnout levels among dentists are low, and the levels of engagement indicate that dentists have a positive working attitude.
\end{abstract}

Within dentistry, chronic work stress and burnout are recognized as potential hazards for both the professional and personal lives of dentists $(1,2)$. In most research, burnout is measured using the Maslach Burnout Inventory (MBI) (3) which distinguishes three aspects of burnout: emotional exhaustion (EE), depersonalization (D), and personal accomplishment (PA). A recent development within burnout research is the shift from the traditional concept and scope to its opposite: work engagement (4-7). This development reflects an emerging trend towards a 'positive psychology' that focuses on human strengths and optimal functioning rather than on weaknesses and malfunctioning (8). In trying to reinforce these strengths, and by striving to promote optimal functioning, it is hoped that work stress and burnout can be prevented.

In early definitions (9), engagement was defined as being the opposite of burnout. As a result, burnout is the negative pole of a continuum, with engagement representing the positive antipode. From this onedimensional view, it would follow that engagement is indicated by a combination of low levels of EE and D and high levels of PA. In positioning burnout and engagement as the end-points of one and the same dimension, the assumption is made that the two opposites are complementary. However, someone who is not burned out cannot automatically be considered engaged (or vice versa) and it is not unlikely that some 
level of engagement and burnout can co-exist. This is also reflected in the measurement of burnout: the MBI is based on frequency scores, and it is possible that someone who indicates experiencing a negative state 'once a week', experiences feelings of joy in the same week.

In reaction to these considerations, Schaufeli \& Bakker developed the Utrecht Work Engagement Scale (UWES), which aims to measure the concept of work engagement as a dimension that is separated from burnout (6). Analogous to burnout, work engagement encompasses three subscales. Vigor (VI) is characterized by high levels of energy and mental resilience while working and by the willingness and ability to invest effort in one's work. Dedication (DED) is characterized by a sense of significance, enthusiasm, inspiration, pride, and challenge. VI and DED are conceived to be the opposite of EE and D, respectively, spanning two dimensions labeled activation (EE-VI) and identification (D-DED). A final scale that is distinguished is absorption (AB), characterized by being fully concentrated and happily engrossed in one's work (5).

Because of their antipodal conceptualization, the empiric relationship between burnout and engagement is of interest. Research in which both the MBI and the UWES were administered indicates a medium to strong negative relationship between the burnout subscales EE and D and the engagement subscales VI and DED. Interestingly, the highest correlation is found between all three UWES subscales and PA. Moreover, support was found for a model that includes a 'core' burnout factor consisting of EE and D, and an extended engagement factor in which PA is incorporated with VI, DED, and AB (5). Thus, there is empiric reason to believe that PA fits better to the more positive, engagement, side than to its origins of burnout.

The first aim of this study was to test the factorial validity of the concept of work engagement among dentists, and its relationship to burnout. No studies exist that examine the structure of engagement among dentists and, additionally, investigate its inherent relationship to burnout. In view of earlier findings (6), it is expected that the three subscales of engagement will be highly related, but that a three-factor structure will find more support than a one-factor structure (hypothesis 1). Furthermore, consistent with the results reported by Schaufeli \& Bakker (5), it is hypothesized that the MBI dimensions (EE, D, and PA) load on 'burnout', whereas the UWES subscales (VI, DED, and AB) load on 'work engagement', and that this model is to be preferred over one, undifferentiating, underlying structure (hypothesis 2). Interestingly, support was also found for a model composed of a 'core' burnout factor consisting of only EE and D, and an extended work engagement factor in which PA is incorporated with VI, DED, and AB (5). On an explorative basis, the current study also investigates the tenability of this model among dentists.

The second aim of this study was to determine the levels of burnout and work engagement within dentistry. As such, it can be considered an extension of earlier research on burnout among dentists (10), as well as an addition to the establishment of research on work engagement among dentists (11). Because in burnout research the possible influences of gender and age have been well described, the correlation of work engagement with age and gender among dentists were also examined.

\section{MATERIAL AND METHODS}

\section{Participants and procedure}

A group of 848 Dutch dentists were randomly selected from the files of Movir Insurances (at the time of the study, $77 \%$ of all Dutch dentists were insured by Movir for inability to work). The sample was stratified for gender, age, and region of practice. All participants were sent a questionnaire (12). Following the recommendations of Dillman (13), the survey included an announcement, two reminders, and (when necessary) complete resending of the questionnaire.

\section{Materials}

A Dutch translation of the MBI $(3,14)$ was used to measure burnout. With the publication of a new manual (15), the Dutch version of the MBI was renamed Utrechtse Burnout Schaal (UBOS). The 20 items of the UBOS can be answered on a 7-point Likert-scale, ranging from 0 ('never') to 6 ('every day'). Three subscale scores can be acquired: EE ( 8 items); D ( 5 items); and PA ( 7 items). Engagement was measured using the 15-item version of the UWES (6). As with the UBOS, scores for each item ranged from 0 ('never') to 6 ('every day'), and three subscale scores were computed (VI, DED, and AB), each consisting of 5 items. 


\section{Statistical analysis}

To address the first aim of the study, the internal consistency of the three UWES subscales was computed using Cronbach's alpha, and interscale correlations were assessed using Pearson's correlations. Structural equation modeling (described in more detail below) was used to further examine the structure of the UWES and its relationship with the UBOS. In addressing the second aim, mean scores and standard deviations were computed and compared with norm scores using multiple analyses of variance (manova). On a more explorative basis, each subscale was correlated with age, and gender differences in the mean score were examined.

To assess the structure of the UWES, three confirmatory factor analytic models were analyzed using the lisrel 8.50 program $(16,17)$. The LISREL Maximum Likelihood estimation procedure was used. Missing data were imputed using the item series mean. Two models were compared with a null model, in which all item scores are uncorrelated. In the first model, the 15 items of the UWES load on a single 'work engagement' scale. The second model tests the proposed three-factor structure of work engagement. To investigate the relationship between burnout and work engagement, three additional models were compared $\left(\mathrm{M}_{1}, \mathrm{M}_{2}\right.$, and $\left.\mathrm{M}_{3}\right)$. The first model $\left(\mathrm{M}_{1}\right)$ is a one-factor model in which the subscales of both UBOS and UWES load on one common factor. In the second model $\left(\mathrm{M}_{2}\right)$, EE, D, and PA load on a common 'burnout' factor, and VI, DED, and AB constitute a 'work engagement' factor. In a third model $\left(\mathrm{M}_{3}\right), \mathrm{EE}$ and $\mathrm{D}$ load on a common 'burnout' factor, and PA, VI, DED and PA load on an 'engagement' factor.

The goodness-of-fit of the models was determined using absolute and relative fit indices. Absolute fit indices were the chi-square goodness-of-fit index $\left(\chi^{2}\right)$, with the accompanying degrees of freedom, and the root mean square error of approximation (RMSEA). Relative fit indices were the non-normed fit index (NNFI), also called the Tucker Lewis Index (TLI), and the Comparative Fit Index (CFI). In contrast to absolute indices, relative indices are independent of sample size and are therefore to be preferred (18). Furthermore, the NNFI is comparably more robust for sample size than either the RMSEA or the CFI (19). The fit of a model is good when the values of the NNFI and the CFI approach 1; higher values represent a better fit. For these indices, most studies consider a value of $\geq 0.90$ as indicative of a good fit. For the RMSEA, values of $<0.06$ imply an acceptable fit (20). The correlation matrices, means, and standard deviations of the data used in the structural equation modelling analyses are available on request.

\section{RESULTS}

\section{Response}

A group of 497 general dental practitioners returned a usable questionnaire (58.6\%). Respondents consisted of 372 men and 121 women (the gender of 4 dentists remained unknown), and the mean age within this group was $44.6 \mathrm{yr}(\mathrm{SD}=9.0)$. The distribution of these and several other descriptive characteristics (i.e. civil status, working hours, number of patients, region of practice) are congruent with the characteristics found in a representative sample taken in $2000(12,21)$. It is therefore safe to assume that the current sample adequately represents the Dutch dental population.

\section{The measurement of burnout and work engagement}

The internal consistencies of the UBOS subscales were highly satisfactory (Cronbach's alpha: EE, 0.90; D, 0.70; and PA, 0.83), and the interscale correlations were comparable to norm scores (EE-D, 0.59; EE-PA, -0.36 ; and D-PA, -0.44). The three UWES subscales also all had high internal consistencies (VI, 0.84; $\mathrm{DED}, 0.90$; and $\mathrm{AB}, 0.82$ ), that showed only minimal deviation from the figures presented in the UWES manual (6). For each scale, all items contributed to the internal consistency. Cronbach's alpha for the UWES as a whole was very high (alpha $=0.94$ ), which is consistent with the alpha of 0.92 reported in the manual. Interscale correlations were 0.77 (VI-DED), 0.80 (VI-AB), and 0.82 (DED-AB). Again, these results are very similar to results reported in the UWES manual.

\section{[TABLE 1]}

Table 1 shows the intercorrelations between the UBOS and UWES subscales for this study and the UWES manual. Apparently, within dentistry, work engagement has a relatively high (negative) relationship with $\mathrm{EE}$, although the pattern (highest correlation between EE and VI, lowest between EE and PA) is identical. Although EE shows the highest correlation with VI, and D correlates highest with DED, these correlations are only marginally higher than the EE-DED or D-VI correlations. These results therefore do not provide 
strong support for the predicted contrasts between VI-EE and between D-DED. On the other hand, the strong correlation of personal accomplishment with work engagement concurs with results found among other professions.

\section{[TABLE 2]}

The results from confirmatory factor analyses are shown in Table 2, together with the results found in the UWES manual (6). The lower chi-square ratio and RMSEA, and the higher NNFI and CFI values, indicate a better fit for the three-factor model compared with the one-factor model. Moreover, only the three-factor model shows an acceptable CFI value. These findings are similar to the results reported by Schaufeli \& Bakker (6), although the figures in the UWES manual suggest a slightly better fit.

\section{[TABLE 3]}

In Table 3 the results are shown of the different combinations of the burnout and work engagement concepts. When considering the absolute values of the fit indices, the results are mixed. None of the models have an acceptable RMSEA value, all models have CFI values that can be considered indicative of an acceptable fit, and only $\mathrm{M}_{3}$ has an acceptable NNFI. However, when comparing the fit indices, a clear pattern emerges. Model $\mathrm{M}_{1}$, in which all subscales load on one general factor, clearly is least fitting, whereas model $\mathrm{M}_{2}$ shows only a slightly better fit. In contrast, the chi-square value and all fit indices are indicative for a superior fit of $\mathrm{M}_{3}$. These results are in line with the results found by Schaufeli et al. (5), also included in Table 3, and demonstrate an even better fit of $\mathrm{M}_{3}$ among dentists. Standardized correlations between burnout and work engagement are -0.88 for $\mathrm{M}_{2}$ and -0.66 for $\mathrm{M}_{3}$. This means that burnout and work engagement share a common variance of $77 \%$ and $44 \%$ for $\mathrm{M}_{2}$ and $\mathrm{M}_{3}$, respectively. With regard to $\mathrm{M}_{3}$, the results correspond to those reported by Schaufeli et al. (5) who found, in a diverse sample of employees, a correlation between burnout and work engagement of -0.62 (representing a common variance of $38 \%)$.

\section{Levels of burnout and work engagement among dentists}

\section{[TABLE 4]}

\section{[TABLE 5]}

Table 4 shows the mean scores for burnout, as well as the norm scores reported in the UBOS manual. As recommended in the UBOS manual, the scores on D are presented separately for men and women. Differences between dentists' results and the figures reported in the manual were small, although the women's D score and the overall PA score were significantly higher $[\mathrm{t}(118)=-3.01, \mathrm{P}=0.003$, and $\mathrm{t}(486)=5.27, \mathrm{P}<0.001$, respectively]. Table 5 shows the mean scores on the three work engagement subscales. On both DED and AB, dentists had a significantly higher score compared with the norms $[\mathrm{t}(490)=8.28, \mathrm{P}<0.001$, and $\mathrm{t}(490)=5.63, \mathrm{P}<0.001$, respectively $]$.

Significant correlations of the three subscales with age were found (ranging between -0.11 for $\mathrm{AB}$ and -0.14 for VI). Interestingly, these correlations were negative, indicating a loss of work engagement with age, whereas the UWES manual reported positive correlations (ranging between 0.05 for VI and 0.17 for $\mathrm{AB})$. To explore this issue further, subscale scores for each of five age groups were computed and compared (Table 6). Multivariate tests indicated significant differences for VI $[F(4)=2.69, \mathrm{P}=0.031]$, $\mathrm{DED}[\mathrm{F}(4)=3.18, \mathrm{P}=0.014]$, and $\mathrm{AB}[\mathrm{F}(4)=2.45, \mathrm{P}=0.045]$. Considering categories 1 (dentists up to $29 \mathrm{yr}$ ) through 4 (up to $59 \mathrm{yr}$ ), within each subscale a pattern emerges of lower mean scores with higher age. Bonferroni post hoc tests indicated that these differences were significant for VI and DED, and only between the youngest dentists and dentists aged 50-59 yr (Table 6 also includes the less restrictive Tukey's Least Significant Difference post hoc results).

\section{[TABLE 6]}

Remarkably, dentists in the highest age group (60 yr and older) had UWES subscale levels that were on a par with those of the youngest dentists, although it should be noted that the highest age group consisted of only 18 dentists. 
Gender differences were only present on the UBOS D scale, which concurs with results reported previously $(15,21)$. Differences between men and women were not found on any of the UWES scales. Again, these results differed from the findings described in the UWES manual, in which men are reported to score significantly higher on DED and AB than women (although these differences were small).

\section{DISCUSSION}

The first aim of this study was to examine the factorial validity of the UBOS and UWES measures among dentists. The results replicated the psychometric properties of the Dutch version of the MBI (or UBOS) by re-establishing the invariance of its three-factor structure when used among dentists. Furthermore, among dentists the concepts of burnout and work engagement were negatively correlated, and the psychometric properties of the new UWES questionnaire were consistent with those reported in the manual. The second aim of this study was to investigate the levels of burnout and work engagement among dentists. The absolute level of EE among dentists did not differ from the norm within general healthcare, whereas female dentists showed a significantly lower level of $\mathrm{D}$, and all dentists indicated higher feelings of PA. These results were consistent with previous findings (22). Compared with the UWES norm scores, dentists were more dedicated and more absorbed in their work, although these levels seemed to decrease with age. In sum, compared with norm scores found among the general Dutch working population, Dutch dentists seem somewhat less burned out and somewhat more engaged in daily work.

Psychometric analyses of the UWES found support for a one-factor solution (given the very high value of Cronbach's alpha), but also for a three-factor solution (given the preference found in model comparison). Interestingly, the alternative model, in which PA is grouped with VI, DED, and AB in an 'enhanced' work engagement factor, and EE and $\mathrm{D}$ in a 'core' burnout factor $\left(\mathrm{M}_{3}\right)$, had a better fit to the data than a theoretically proposed model of work engagement and burnout. Among dentists, burnout and work engagement are negatively correlated. However, although the common variance (44\%) is higher than reported by Schaufeli, more than half of the variance is unique, underscoring the usefulness of a distinct concept of 'work engagement'.

Why does PA load on the 'wrong' factor? Two main reasons can be proposed. First, it is possible that the positive phrasing of the PA items - which coincides with the phrasing of the work engagement items, but is inconsistent with the negative phrasing of $\mathrm{EE}$ and $\mathrm{D}-$ is of influence. This notion is supported by the results reported by Bouman et al. (23). Alternatively, these results could also be indicative of the awkward position of PA within the concept of burnout. Whereas $\mathrm{D}$ is supposed to be a consequence of EE (a notion that is supported by the high correlations between these scales that are typically found), PA is repeatedly found to have a somewhat independent role $(10,24-26)$.

No clear support was found for the assumption that VI and DED are the opposites of EE and D, respectively. Although the negative relationship between EE and VI was somewhat higher than the D-VI relationship, the D-DED correlation showed only minimal deviation from the EE-DED correlation. This latter result also contrasts with the particularly strong D-DED relationship reported in the UWES manual. The highest correlations were found between PA and all subscales of work engagement. This is in concurrence both with the UWES manual figures, as well as with the finding that a model of work engagement, which includes the PA subscale, best fits the data.

It is noteworthy that Dutch dentists have a generally positive working attitude. It was also interesting to find a trend of declining work engagement with higher age, although the oldest dentists again have a fairly high engagement level. The latter finding can presumably be explained by a selection effect: only the most 'engaged' dentists are still working at an old age. However, this study was restricted to the working situation of dentists in the Netherlands. Further research in other countries and occupational settings is needed to shed more light on these findings and possibly replicate and strengthen them. Additional research is also essential to extend further our knowledge of work engagement and its relationship to burnout, and it may give rise to the construction of new models in addition to the three models tested in the current study.

We hope that increased attention to the positive side of work experience will inspire a closer examination of the important correlates of the work engagement scales. Burnout research has shown that the three MBI subscales differ in their antecedents and consequences (24), and that, within dentistry, specific job demands can be identified that are associated with higher levels of work-related stress and burnout (27). In the same vein, research on work engagement can yield practical implications of the construct of work engagement. In a recent study, specific positive aspects of the dental work were specified (28). The identification and 
H. Brake; A.M. Bouman; R. Groter; J. Hoogstraten; M. Eijkman.

Professional burnout and work engagement among dentists.

European Journal of Oral Sciences. Vol. 115, 2007, nr. 3, p. 180-185.

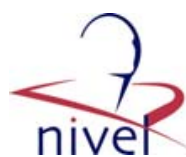

promotion of these positive aspects can serve to enhance overall work engagement, and conceivably it will even prove to be a very practical way to prevent future burnout among dentists.

\section{ACKNOWLEDGEMENTS}

This study was financially supported by Movir Insurance, Nieuwegein, the Netherlands.

TABLES

Table 1

Correlations between the Utrechtse Burnout Schaal (UBOS) subscales (EE, D, and PA) and the Utrecht Work Engagement Scale (UWES) subscales (VI, DED, and $A B$ ), for the current study and as reported in the UWES manual $(n=9,679)$

\begin{tabular}{lrrrrrrr}
\hline & \multicolumn{3}{c}{ Current study } & & \multicolumn{3}{c}{ UWES manual } \\
\cline { 2 - 3 } \cline { 6 - 7 } & VI & DED & AB & & VI & DED & AB \\
\hline EE & -0.55 & -0.46 & -0.38 & & -0.38 & -0.26 & -0.15 \\
D & -0.44 & -0.50 & -0.38 & & -0.50 & -0.66 & -0.46 \\
PA & 0.63 & 0.69 & 0.58 & & 0.66 & 0.67 & 0.50 \\
\hline
\end{tabular}

All correlations, $P<0.01$.

$\mathrm{AB}$, absorption; D, depersonalization; DED, dedication; EE, emotional exhaustion; PA, personal accomplishment; VI, vigor.

Table 2

Structural fit of one-factor and three-factor solutions of the Utrecht Work Engagement Scale (UWES)

\begin{tabular}{lrrrll}
\hline Model & \multicolumn{1}{c}{$\chi^{2}$} & d.f. & RMSEA & NNFI & CFI \\
\hline Current study & & & & & \\
$\quad$ Null model & 4990.91 & 105 & 0.53 & 0.0 & 0.0 \\
$\quad$ One-factor model & 622.11 & 90 & 0.12 & 0.87 & 0.89 \\
$\quad$ Three-factor model & 518.80 & 87 & 0.11 & 0.89 & 0.91 \\
UWES manual & & & & & \\
$\quad$ One-factor model & 10937.76 & 90 & 0.11 & 0.87 & 0.89 \\
$\quad$ Three-factor model & 7789.57 & 87 & 0.10 & 0.90 & 0.92
\end{tabular}

CFI, comparative fit index; $\chi^{2}$, chi-square goodness-of-fit index; d.f., degrees of freedom; NNFI, non-normed fit index; RMSEA, root mean square error of approximation. 
Table 3

Measuring the fit of different models utilizing the Utrechtse Burnout Schaal (UBOS) and the Utrecht Work Engagement Scale (UWES) subscales

\begin{tabular}{|c|c|c|c|c|c|}
\hline Model & $\chi^{2}$ & d.f. & RMSEA & NNFI & $\mathrm{CFl}$ \\
\hline \multicolumn{6}{|c|}{ Current study } \\
\hline $\mathrm{M}_{1}$ & 206.06 & 9 & 0.20 & 0.84 & 0.90 \\
\hline $\mathrm{M}_{2}$ & 178.53 & 8 & 0.20 & 0.85 & 0.92 \\
\hline $\mathrm{M}_{3}$ & 96.15 & 8 & 0.15 & 0.92 & 0.96 \\
\hline \multicolumn{6}{|c|}{ SCHAUFELI et al. (5) } \\
\hline $\mathrm{M}_{1}$ & 451.64 & 18 & 0.16 & 0.72 & 0.83 \\
\hline $\mathrm{M}_{2}$ & 402.70 & 16 & 0.16 & 0.72 & 0.85 \\
\hline $\mathrm{M}_{3}$ & 216.29 & 18 & 0.11 & 0.87 & 0.92 \\
\hline
\end{tabular}

Table 4

Mean scores ( $M$ ) and standard deviations (SD) on the burnout subscale for dentists compared with norm scores $(6,15)$

\begin{tabular}{llllll}
\hline & \multicolumn{2}{c}{$\begin{array}{c}\text { Current study } \\
(n=487)\end{array}$} & & \multicolumn{2}{c}{$\begin{array}{c}\text { UBOS manual } \\
(n=10,552)\end{array}$} \\
\cline { 2 - 3 } \cline { 6 - 7 } & $\mathrm{M}$ & $\mathrm{SD}$ & & $\mathrm{M}$ & $\mathrm{SD}$ \\
\hline EE & 1.75 & 1.07 & & 1.81 & 1.00 \\
D men & 1.34 & 0.84 & & 1.27 & 0.84 \\
D women* & 1.00 & 0.68 & & 1.14 & 0.78 \\
PA* & 4.42 & 0.84 & & 4.22 & 0.78 \\
\hline
\end{tabular}

"Significantly different from norm scores $(P<0.01)$.

$\mathrm{D}$, depersonalization; EE, emotional exhaustion; PA, personal accomplishment; UBOS, Utrecht BurnOut Scale. 
Table 5

Mean scores $(M)$ and standard deviations (SD) on the positive engagement subscale for dentists compared with norm scores $(6,15)$

\begin{tabular}{lccccc}
\hline & \multicolumn{2}{c}{$\begin{array}{c}\text { Current study } \\
(n=491)\end{array}$} & & \multicolumn{2}{c}{$\begin{array}{c}\text { UWES manual } \\
(n=9,679)\end{array}$} \\
\cline { 2 - 3 } \cline { 6 - 7 } & $\mathrm{M}$ & $\mathrm{SD}$ & & $\mathrm{M}$ & $\mathrm{SD}$ \\
\hline VI & 3.95 & 1.13 & & 3.99 & 1.10 \\
DED $^{*}$ & 4.32 & 1.09 & & 3.91 & 1.31 \\
AB $^{*}$ & 3.86 & 1.09 & & 3.58 & 1.18 \\
\hline
\end{tabular}

"Significantly different from norm scores $(P<0.01)$.

$\mathrm{AB}$, absorption; DED, dedication; UWES, Utrecht Work Engagement Scale; VI, vigor.

\section{Table 6}

Age and engagement: differences between age categories, mean scores ( $M)$ and standard deviations (SD) for each Utrecht Work Engagement Scale (UWES) subscale

\begin{tabular}{|c|c|c|c|c|c|c|c|}
\hline & \multicolumn{4}{|c|}{ Age category (yr) } & \multirow[b]{2}{*}{$\mathrm{n}$} & \multirow[b]{2}{*}{$\mathrm{M}$} & \multirow[b]{2}{*}{$\mathrm{SD}$} \\
\hline & $30-39$ & $40-49$ & $50-59$ & $>60$ & & & \\
\hline \multicolumn{8}{|l|}{ VI } \\
\hline$<29$ & -0.3 & $-0.5^{*}$ & $-0.6 * *$ & -0.3 & 31 & 4.4 & 1.0 \\
\hline $30-39$ & & -0.2 & $-0.3^{*}$ & 0.0 & 105 & 4.1 & 1.0 \\
\hline $40-49$ & & & -0.1 & 0.2 & 194 & 3.9 & 1.0 \\
\hline $50-59$ & & & & 0.3 & 140 & 3.8 & 1.3 \\
\hline$>60$ & & & & & 18 & 4.1 & 1.4 \\
\hline \multicolumn{8}{|l|}{ DED } \\
\hline$<29$ & -0.4 & $-0.6^{*}$ & $-0.7 * *$ & -0.3 & 31 & 4.8 & 0.9 \\
\hline $30-39$ & & -0.2 & $-0.3 *$ & 0.0 & 105 & 4.5 & 1.0 \\
\hline $40-49$ & & & -0.1 & 0.3 & 194 & 4.2 & 1.1 \\
\hline $50-59$ & & & & 0.3 & 140 & 4.2 & 1.2 \\
\hline$>60$ & & & & & 18 & 4.5 & 0.9 \\
\hline \multicolumn{8}{|l|}{$\mathrm{AB}$} \\
\hline$<29$ & -0.3 & $-0.5^{*}$ & $-0.5^{*}$ & -0.2 & 31 & 4.3 & 1.1 \\
\hline $30-39$ & & -0.2 & -0.2 & 0.1 & 105 & 4.0 & 1.1 \\
\hline $40-49$ & & & 0.0 & 0.3 & 194 & 3.8 & 1.0 \\
\hline $50-59$ & & & & 0.3 & 140 & 3.8 & 1.2 \\
\hline$>60$ & & & & & 18 & 4.1 & 1.1 \\
\hline
\end{tabular}

*Significant difference (Tukey's Least Significant Difference post hoc test, $P<0.05$ ).

"Significant difference (Bonferroni post hoc test, $P<0.05$ ). $\mathrm{AB}$, absorption; DED, dedication; n, number of subjects; VI, vigor. 


\section{REFERENCES}

1. Humphris G. A review of burnout in dentists. Dent Update 1998; 25: 392-396.

2. Rada RE, Johnson-Leong C. Stress, burnout, anxiety and depression among dentists. J Am Dent Assoc 2004; 135: 788-794.

3. Maslach C, Jackson SE, Leiter MP. MBI manual, 3rd edn.

Palo Alto, CA

: Consulting Psychologists Press, 1996.

4. Schaufeli WB, Mártinez IM, Marques Pinto A, Salanova M, Bakker AB. Burnout and engagement in University students. A cross-national study. J Cross Cult Psychol 2002; 33: 464-481.

5. Schaufeli WB, Salanova M, González-Romá V, Bakker AB. The measurement of engagement and burnout: a two sample confirmatory factor analytic approach. J Happ Stud 2002; 3: 71-92.

6. Schaufeli WB, Bakker AB. UWES. Utrecht work engagement scale. Preliminary manual, Version 1. Utrecht

: Utrecht University Occupational Health Psychology Unit, 2003.

7. Schaufeli WB, Bakker AB. Job demands, job recourses and their relationship with burnout and engagement: a multi-sample study. J Org Behav 2004; 25: 293-315.

8. Seligman MEP, Csikszentmihalyi M. Positive psychology: an introduction. Am Psychol 2000; 55: 514.

9. Maslach C, Leiter MP. The truth about burnout: how organizations cause personal stress and what to do about it San Francisco, CA: Jossey-Bass, 1997.

10. Gorter RC, Albrecht G, Hoogstraten J, Eijkman MAJ. Factorial validity of the Maslach Burnout Inventory - Dutch Version (MBI-NL) among dentists. J Organ Behav 1999; 20: 209-217.

11. Hakanen JJ, Bakker AB, Demerouti E. How dentists cope with their job demands and stay engaged: the moderating role of job resources. Eur J Oral Sci 2005; 113: 479-487.

12. Te Brake JHM. Burnout and job engagement in dentistry. Amsterdam, the Netherlands: Universiteit van Amsterdam, 2005.

13. Dillman DA. Mail and telephone surveys. The total design method. New York: John Wiley \& Sons, 1978.

14. Schaufeli WB, Van Dierendonck D. Maslach burnout inventory, Dutch version (MBI-NL).

Provisional manual. Utrecht, the Netherlands: Utrecht University, Research School Psychology \& Health, 1995.

15. Schaufeli WB, Van Dierendonck D. Utrechtse burnout schaal. Handleiding (Dutch MBI-NL Manual). Lisse, the Netherlands: Swets \& Zeitlinger B.V., 2000.

16. Jöreskog KG, Sörbom D. LISREL 8.54. (Windows). Chicago, IL: Scientific Software International, 2001.

17. Jöreskog KG, Sörbom D. Lisrel: User's reference guide. Chicago, IL: Scientific Software International, 1996.

18. Bentler PM. Comparative fit indexes in structural models. Psychol Bull 1990; 107: 238-246.

19. Marsh HW, Balla JR, McDonald RP. Goodness-of-fit indexes in confirmatory factor analysis: the effect of sample size. Psychol Bull 1988; 103: 391-410.

20. Hu L, Bentler PM. Cutoff criteria for fit indexes in covariance structure analysis: conventional criteria versus new alternatives. Struct Equation Model 1999; 6: 1-55.

21. Te Brake JHM, Bloemendal E, Hoogstraten J. Gender differences in burnout among Dutch dentists. Community Dent Oral Epidemiol 2003; 31: 321-327.

22. Gorter RC, Albrecht G, Hoogstraten J, Eijkman MAJ. Professional burnout among Dutch dentists. Community Dent Oral Epidemiol 1999; 27: 109-116.

23. Bouman AM, Te Brake JHM, Hoogstraten J. Significant effects due to rephrasing the Maslach

Burnout Inventory's personal accomplishment items. Psychol Rep 2002; 91: 825-826.

24. Lee RT, Ashforth BE. A meta-analytic examination of the correlates of the three dimensions of job burnout. J Appl Psychol 1996; 81: 123-133.

25. Maslach C, Schaufeli WB, Leiter MP. Job burnout. Annu Rev Psychol 2001; 52: 397-422.

26. Leiter MP. Burnout as a developmental process: consideration of models. In: Schaufeli WB, Maslach

C, Marek T, eds. Professional burnout: recent developments in theory and research Washington, DC:

Taylor \& Francis, 1993; 237-250. 
H. Brake; A.M. Bouman; R. Groter; J. Hoogstraten; M. Eijkman.

Professional burnout and work engagement among dentists.

European Journal of Oral Sciences. Vol. 115, 2007, nr. 3, p. 180-185.

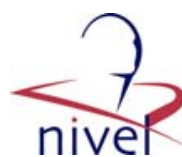

27. Gorter RC, Albrecht G, Hoogstraten J, Eijkman MAJ. Work place characteristics, work stress and burnout among Dutch dentists. Eur J Oral Sci 1998; 106: 999-1005.

28. Gorter RC, Te Brake JHM, Hoogstraten J, Eijkman MAJ. Positive engagement and job resources in dental practice. Community Dent Oral Epidemiol: in press. 